\title{
Risk externalities in a payments oligopoly
}

\author{
Tore Nilssen
}

Received: 8 December 2009 / Accepted: 4 October 2010 / Published online: 27 October 2010 (C) The Author(s) 2010. This article is published with open access at Springerlink.com

\begin{abstract}
I discuss the role to be played by central banks in payment systems by way of an oligopoly model of a payments market where firms exert negative risk externalities upon each other. A central bank participating actively in this market is modelled as benign in two ways: exerting less externalities than other banks and maximizing welfare rather than profit. Because other banks react strategically to the central bank's presence due to its low externalities, there is a risk that it backfires, with these other banks' taking more risky positions than if the central bank were not there. The proper role of the central bank may actually be to stay out.
\end{abstract}

Keywords Payments • Risk externalities • Interbank market • Mixed oligopoly $\cdot$ Central bank

JEL Classification $\mathrm{G} 21 \cdot \mathrm{D} 43 \cdot \mathrm{E} 58 \cdot \mathrm{L} 13$

\section{Introduction}

In the aftermath of the recent financial crisis, the US Board of Governors of the Federal Reserve System have announced a new policy on payment system risk, in which the central bank will be playing a greater role than it did before. ${ }^{1}$ In this paper, I argue, however, that there are good reasons to be cautious about the central bank's role in the market for payments. \footnotetext{
take effect late 2010 or early 2011.

T. Nilssen $(\varangle)$

Department of Economics, University of Oslo, P.O. Box 1095 Blindern,

0317 Oslo, Norway

e-mail: tore.nilssen@econ.uio.no
}

${ }^{1}$ See Board of Governors of the Federal System (2008) for details on the new policy, which will 
Banks operating in the payments market exert negative risk externalities on each other. A role for the central bank to play in this market could be as a balancing of two concerns that these externalities raise: On one hand, a central bank never gets illiquid and therefore exerts less negative externalities than what other banks in the market do; this calls for a large role of the central bank in the payment system. On the other hand, negative externalities imply that the equilibrium quantity supplied in the market is too high relative to social optimum. But the presence of a central bank, with its benign externalities, will cause the other banks to increase their activities. As my analysis below will show, this strategic response by the other banks to the presence of the central bank may call for a reduction in the central bank's activities-despite it being more efficient than the others-and perhaps even a total abstention.

In order to model this trade-off, I propose a stylized model of the market for payments as an oligopoly facing a downward-sloping demand; thus, the number of payments carried out in the economy will depend on the price charged for the payment service. Although there, in general, is undersupply in the equilibrium of an oligopoly, compared to the social optimum, this outcome may not hold true when the oligopolists' activities exert negative externalities. ${ }^{2}$

In Section 2 of this paper, I briefly present the payments system and the externalities involved. In the payments industry, a payment may involve one bank (the payee's bank) extending intra-day credit to another bank (the payer's bank) until the payment is settled. One bank's provision of services thus exerts negative risk externalities on other banks. There are two kinds of risk externalities involved. First, when one bank extends credit to another bank, the first bank does not take into account, in its assessment of this business, how extending this credit affects the other bank's ability to honor its debt to third-parties; this is a credit-risk externality. Secondly, and importantly, the first bank does not take into account the effect a failure by the other bank in honoring the debt may affect its own ability to honor its debt to third-parties; this is a systemic-risk externality. The Section ends with a brief overview of related literature.

In Section 3, I present my model of banks participating in this payments system and, in so doing, interacting strategically and exerting negative risk externalities upon each other. In the model, the demand for payment services is price sensitive, as discussed above. Moreover, the central bank is modelled as differing from the other banks on two counts. First, it is publicly owned and is therefore maximizing welfare. Secondly, since the central bank itself cannot become illiquid, it does not exert any systemic-risk externality.

In Section 4, I present three different scenarios: one in which all banks are private and profit-maximizing; one in which one of the banks is a publicly

\footnotetext{
${ }^{2}$ One commonly discussed case is that of pollution. The observation that a monopolist exerting negative externalities does not necessarily produce less than what is socially optimal dates back at least to Buchanan (1969). Among law scholars, there has been a discussion on the proper antitrust policy in industries with negative externalities from production or consumption; see, e.g., Leslie (1993), Hammer (2000), and Crane (2005).
} 
owned bank with the aim of maximizing welfare; and one in which the publicly owned bank in addition also is the central bank. Since the central bank cannot possibly become illiquid, the risk externalities associated with its activities are different from those of the other banks.

In Section 5, I find the socially optimum outcome in this market, account taken, by a social planner, of all externalities.

In Section 6, I analyze and compare the equilibrium outcomes in the various scenarios outlined in Section 4. In particular, the central bank may have to trade off the more moderate risk externalities it exerts itself with a too high credit level from the private part of the market. Thus, even if the first best calls for the central bank to be the largest, it may well end up the smallest bank in equilibrium. In this Section, I also compare the equilibrium outcomes and the social optima in the various scenarios. Interestingly, introducing the central bank, thus reducing overall risk externalities in this market, may actually increase the scope for an oversupply of credit in equilibrium, because the private banks get much more aggressive in their extension of intra-day credit when their public counterpart is a benign central bank than when it is just an ordinary bank, albeit a welfare-maximizing one.

Section 7 contains concluding remarks, while the Appendix contains more detailed results than what is in the main text, as well as proofs.

\section{Externalities in the payments system}

Payments flow among the banks in a modern economy. Of particular interest here are large-value transfers; in 2008, according to reports from BIS, payments through the two large-value transfer systems in the US totalled $\$ 1,263$ trillion. $^{3}$

There are essentially two kinds of large-value payments system in use: Real Time Gross Settlement (RTGS) and Deferred Net Settlement (DNS). In a DNS system, most payments are based on a credit extended temporarily, and often implicitly, among the banks until the payment is settled later in the day. Thus, these payment flows necessitate a lot of intra-day (sometimes called "daylight") credit. In recent years, many countries have switched from a DNS system to an RTGS system, which reduces the credit risk involved without eliminating it: as far as possible, gross payments are settled instantly in an RTGS system, but a lack of liquidity in a payer's bank may make it necessary to put off settlement also for payments in this kind of system.

Like other banking markets, the intra-day credit market may suffer from distortions caused by the market power of individual banks. In this paper, I present a model of an intra-day credit oligopoly with two idiosyncratic features in addition to the market power of the banks participating. First, there are

\footnotetext{
${ }^{3}$ The two are CHIPS (the Clearing House Interbank Payments System) and Fedwire. This number, and many others, can be extracted from Committee on Payment and Settlement Systems (2009). Small-value transfers, which are the means by which the average household makes its payments, do not give rise to intra-day credit.
} 
negative risk externalities among the banks: increased credit extended by one bank increases not only its own risk but also the risk of the other banks that are active in this market. Secondly, the central bank plays a role in this market, a role which has to be modelled properly. In this paper, the central bank differs from the private banks in two ways. First, the central bank is a welfare maximizer, trying to correct as far as possible the combined distortions created by the oligopolistic market structure and the negative risk externalities. Secondly, the central bank, never becoming illiquid, imposes less of a negative externality than a private bank does.

With this latter aspect of the central bank, the analysis makes an interesting twist on the literature of mixed oligopoly (e.g., De Fraja and Delbono 1990): In my analysis, the public firm has the double feature of being both welfare maximizing in its objectives and comparatively efficient in its technology. When the private-banks-only equilibrium features too much credit compared to the first-best social optimum, because the underproduction tendency of the oligopoly is overturned by the overproduction tendency due to the negative risk externality, the two features of the central bank clash: With the central bank present in the market, it seeks to correct the distortion. But should it produce less than a private bank would, in order to correct the overproduction, or should it produce more in light of it being more efficient? The present analysis throws some light on these and related issues.

Berger et al. (1996) provide an account of the various risks and costs involved in the operation of payments systems. In particular, they introduce the risk-cost frontier of a payments system: Risks may be kept down but only at a cost. As discussed by Berger et al., there are many kinds of risk involved in a payment system. In the present analysis, I concentrate on contagion risk: If one bank becomes illiquid, then inter-bank lending and the resulting financial interdependence may cause other banks also to become illiquid. ${ }^{4}$

To be specific, consider a case of a DNS system operated by three banks, called A, B, and C. Suppose a client of bank B wants to make a payment to a client of bank A. If it accepts this payment to be made, bank A extends an intra-day credit to bank B by transferring the payment immediately to its client, even though the payment is not finalized, i.e. the amount is not transferred from bank B to bank A until settlement time later in the day.

When bank A considers extending credit to bank B, bank A takes into account the possibility that bank B-by this way becoming more indebtedhas an increased chance of becoming illiquid before settlement time, as well as the credit risk this possibility imposes on it. ${ }^{5}$ This risk to bank $\mathrm{A}$ that the payment will not be finalized in case the borrower defaults on its obligations during the day is the bank's internal direct credit risk.

\footnotetext{
${ }^{4}$ See, e.g., Kaufman (1994), Angelini et al. (1996), and Shen (1997).

${ }^{5}$ The credit risk can in a way be seen as stemming from the increased intraday debt of the borrowing bank interacting with its overall intraday liquidity management.
} 
But also other lenders to the borrowing bank are affected by it getting more indebted. In particular, when a bank extends credit to another bank, this increases the borrowing bank's debt and thus the probability that third banks, who also have credit outstanding with that borrowing bank, will suffer a loss. Bank A does not, however, take into account this risk that its credit to bank B imposes on bank C, who also extends credit to bank B; this is the external direct credit risk associated with bank A's credit to bank B.

And finally, there is still another risk externality involved. The systemic risk relates to losses incurred by third parties when a lender's borrower defaults and the lender then in turn defaults on its obligations. Consider again the case where bank A extends credit to bank B. If bank B becomes illiquid, then bank A itself may turn illiquid and bank C, extending credit to bank A as well, may suffer a credit risk this way; this is the systemic risk associated with bank A's credit to bank B.

Below, I analyze the implication of the presence of these risk externalities for the performance of the intra-day credit market, and thus of the payments system, taking explicitly into consideration the effect of strategic interaction among the banks.

In order to focus on these strategic effects on the functioning of a largevalue transfer system, I disregard several other important aspects of such payment systems that are discussed elsewhere. These other aspects include: how to design a payment system (Freixas and Parigi 1998; Kahn and Roberds 1998; Kahn et al. 2003; Fujiki et al. 2008); how to regulate the participants in a payment system (Rochet and Tirole 1996a; Hancock and Wilcox 1996; Freixas et al. 2000); and the scope for self-regulation through peer monitoring and the like (Rochet and Tirole 1996b; Calomiris and Kahn 1996; Rolnick et al. 1998, 2000).

An interesting analysis of strategic interaction in a payments system is the one by Angelini (1998) on strategic behavior in an RTGS system. ${ }^{6}$ In order to study such a system, he develops a dynamic model and traces payments over time during a business day. The model that I present below is designed to focus on the role of the central bank through active participation in the payment system. Therefore, I abstract from the dynamics that is at the heart of Angelini's analysis and instead present a static model of the strategic interaction.

Strategic interaction is the focus also of Kauko's (2009) analysis. Moreover, like me, he discusses the role of the central bank in a mixed-oligopoly setting. However, he disregards the negative risk externalities involved in the payments system, which is central to the present concern, focusing instead on positive network externalities. In a sense, the two analyses complement each other by emphasizing different sets of externalities that may arise in a payments system.

\footnotetext{
${ }^{6}$ See also Bech and Garratt (2003) for a related study.
} 
Closer to my concerns is the analysis of Holthausen and Rochet (2006). Like me, they posit a downward-sloping demand for payments services and are concerned with a case of mixed oligopoly. But there are also some differences in the modelling approach. They discuss a situation where banks act as consumers, seeking payment services from either a central bank or a private payments system, whereas I have the banks-out of which one may be the central bank-as suppliers of payment services to the public. The private payment system is set to price at average costs, which restricts the scope for strategic responses from private providers of payment services to the activities of the central bank, which is at the heart of the present study.

Note, finally, that my call for the central bank to play an, at best, modest role in the payment system is in line with views aired by such scholars as Green and Todd (2001) and Lacker (2008), arguing essentially that the central bank's presence has negative moral-hazard effects on the other banks' behaviour. While this argument has the same flavour as mine, they do not carry out any formal analysis in order to see how the two benign properties of a central bank, exerting less negative externalities and maximizing welfare, interact.

\section{A model of intra-day credit}

My model is a highly stylized picture of what is actually going on in a payments system. In the intra-day credit market, a bank's demand for credit is derived from that of the clients it serves. I assume that the number of lending banks is exogenously fixed. To begin with, all lending banks are assumed to be private. Later on, the issue will be what difference it makes whether one of the banks is publicly owned, with an objective to maximize welfare, and eventually what happens if the publicly owned bank in addition is a central bank that cannot become illiquid (i.e., a lender of last resort).

Let there be $n \geq 3$ banks who extend credit to each other in a DNS payments system. ${ }^{7}$ The amount of credit extended by bank $i$ is denoted $q_{i} \geq 0, i \in N:=$ $\{1, \ldots, n\}$; note that this consists of a number of gross credits extended by a bank when it accepts to perform a payment to one of its own clients from some other bank's client before the payment has been settled between the banks. Let $q_{i j}$ denote the amount of credit extended by bank $i$ to bank $j$. I assume for simplicity that a bank extends equal amounts of credit to the other banks, so that:

$$
q_{i j}=\frac{1}{1-n} q_{i}, \quad i, j \in N, \quad i \neq j .
$$

In line with practice in most countries, there is no charge on an intra-day loan. The income received by a bank comes from fees paid by the paymentdemanding public. The demand for intra-day credit is thus derived from the

\footnotetext{
${ }^{7}$ With $n=2$, there would be no externalities involved; see the discussion below.
} 
underlying demand for intra-day payment services. In particular, it is assumed to be given by the following linear inverse demand function:

$$
p=p(Q)=a-b Q
$$

where $Q:=\sum_{i \in N} q_{i}$ is the total quantity of credit supplied, and $a, b>0$. Note that $p$ is not the interbank credit rate but the marginal willingness to pay among consumers of payment services. It seems reasonable to allow the demand for payment services to depend on the functioning of the interbank market. ${ }^{8}$

I consider all interday, or long-term, credit as exogenous to the current problem; to ease notation, I normalize long-term credit at zero.

The technological costs to a bank of extending an amount $q$ of credit is given by $\frac{c}{2} q^{2}$, where $c>0$. In addition, there are costs associated with the risk of the intra-day credit that is extended. I assume that banks are risk neutral and that the expected loss per unit of credit is increasing in the amount extended: $\frac{d}{2} q$. This implies that a bank's total internal direct credit risk is $\frac{d}{2} q^{2}$, where $d>0$.

In our partial-equilibrium framework, welfare is the sum of consumer and producer surpluses, account taken of the externalities. There are two kinds of externalities. ${ }^{9}$ First, there is the external direct credit risk: Each dollar lent by a bank to another bank is a cost not only to the lender, but to any third bank as well. In particular, for each unit of credit extended to bank $k$ by other banks, there is a credit risk imposed on bank $j$ equal to $\frac{d}{2} q_{j}$. Thus, the external direct credit risk that bank $i$ imposes on bank $j$ by extending credit to bank $k$ equals

$$
\frac{d}{2} q_{i k} q_{j}=\frac{d}{2} \frac{1}{1-n} q_{i} q_{j}
$$

For each third bank $j$, there are $(n-2)$ banks $k$ through which this externality works. Thus, the external direct credit risk that bank $i$ imposes on bank $j$ is

$$
\frac{d}{2} \frac{n-2}{n-1} q_{i} q_{j}
$$

\footnotetext{
${ }^{8}$ The assumption that $p$ depends on $Q$, or, vice versa, that demanded payment quantity depends on the price charged for payments, contrasts with that of Berger et al. (1996), who base their discussion of the risk-cost trade-off in payment systems on the quantity of payment being fixed. It is, however, consistent with the empirical evidence that is available for the price sensitivity of small-value payments (Humphrey et al. 1996, 2001). There do not seem to exist any similar studies on large-value payments. However, there is no reason to believe results would be much different. Linearity is assumed here for simplicity. While there is no reason to believe payment demand is price sensitive for very low prices, linearity and a finite $b$ may be a good local approximation when firms have market power as they have here.

${ }^{9}$ My way of modelling the externalities follows that of Gelfand and Lindsey (1989). They do not consider the case of oligopoly, though. In addition, they do not take into account that externalities are suffered by third banks only; see below.
} 
so that the external credit risk imposed by the lending activity of bank $i$ is, all in all,

$$
\frac{d}{2} \frac{n-2}{n-1} q_{i} \sum_{j \neq i} q_{j}
$$

Similarly, the external credit risk imposed upon bank $j$ by the collective lending activity by other banks is:

$$
\frac{d}{2} \frac{n-2}{n-1} q_{j} \sum_{i \neq j} q_{i}
$$

Secondly, there is the systemic risk, which operates in the same way as the external direct credit risk. ${ }^{10}$ In order to simplify, I assume that the strength of the two externalities is the same, i.e., I use the risk parameter $d$ also for the systemic risk. This means that the systemic risk caused by the lending activity of bank $i$ is another

$$
\frac{d}{2} \frac{n-2}{n-1} q_{i} \sum_{j \neq i} q_{j}
$$

As above, the systemic risk imposed upon bank $j$ by all other banks' lending activity is:

$$
\frac{d}{2} \frac{n-2}{n-1} q_{j} \sum_{i \neq j} q_{i}
$$

Total social risk, i.e., internal and external direct credit risk and systemic risk over all banks, now equals:

$$
\frac{d}{2} \sum_{i} q_{i}^{2}+d \frac{n-2}{n-1} \sum_{i} \sum_{j \neq i} q_{i} q_{j} .
$$

With the specified inverse demand, total gross benefit from a credit quantity $Q$ equals $\left(a Q-\frac{b}{2} Q^{2}\right)$. Thus, welfare is:

$$
\begin{aligned}
W:= & a\left(\sum_{j \in N} q_{j}\right)-\frac{b}{2}\left(\sum_{j \in N} q_{j}\right)^{2}-\frac{c}{2}\left(\sum_{j \in N} q_{j}^{2}\right)-\frac{d}{2}\left(\sum_{j \in N} q_{j}^{2}\right) \\
& -d \frac{n-2}{n-1}\left(\sum_{\substack { i \in N \\
\begin{subarray}{c}{j \in N \\
j \neq i{ i \in N \\
\begin{subarray} { c } { j \in N \\
j \neq i } }\end{subarray}} q_{i} q_{j}\right) .
\end{aligned}
$$

For simplicity, I assume that all revenue from performing payment services accrues to the bank of the client receiving the payment, i.e., to the bank

\footnotetext{
${ }^{10}$ As we shall see later, introducing a lender of last resort will imply a distinction between the two kinds of external risk. 
extending intra-day credit. In calculating its payoff, private bank $i$ takes into account revenues, technological costs, the internal direct credit risk, and the credit-risk externalities imposed on him by the other lenders. Thus, bank $i$ 's profit is:

$$
\pi_{i}=\left(a-b \sum_{j \in N} q_{j}\right) q_{i}-\frac{c}{2} q_{i}^{2}-\frac{d}{2} q_{i}^{2}-d \frac{n-2}{n-1}\left(\sum_{\substack{j \in N \\ j \neq i}} q_{j}\right) q_{i} .
$$

Note from the last term in the above expression that, although the external credit risk and systemic risk are imposed upon a bank by the activities of other banks, the extent to which each bank is exposed to these externalities can be decreased by the bank reducing its own activity in the market.

\section{Three different scenarios}

Although the activities of the central bank is the ultimate focus of interest in this analysis, I present three different scenarios of the payments system and the intra-day credit market. In the first scenario, all the $n$ banks operating in the payment system are private and thus maximizing profits. This scenario is of interest in its own right, because the analysis of it highlights the contrast between the tendency towards undersupply because of oligopoly and the tendency towards oversupply because of negative externalities.

In the second scenario, one of the banks is made into a publicly owned bank with the aim of maximizing welfare. Apart from this difference in objective, this bank is like the other banks; in particular, it is as likely as any other bank to become illiquid.

The existence of a publicly owned bank is interesting for at least two reasons. First, the intra-day credit market is very difficult to regulate from above, particularly in a net-settlement payments system, where there is little supervision of credit flows during the business day. In such a case, it is interesting to see if there is anything to gain from "regulating from within" with the help of a welfare-maximizing participant in the market.

Secondly, there do in fact exist publicly owned banks in many countries: The central bank is typically publicly owned, but in addition also other parts of the banking industry may be so. It may be doubtful whether such banks perform differently from their private counterparts; it may, in fact, be that the government keeps the public bank for enhancement of fiscal revenue rather than for welfare maximization. Presently, however, I will argue that using the public bank as an instrument for regulating the intra-day credit market from within is an alternative worth considering.

I therefore, in this scenario, perform the following exercise: I transform one of the private banks of the previous scenario into a publicly owned, welfaremaximizing one; thus, there are now $n-1$ private banks and one public one. 
Apart from the ownership status and the difference in the banks' objectives that this entails, the banks are identical.

In the third and final scenario, I take into account that the publicly owned bank, if it is also the central bank, cannot become illiquid and therefore imposes less external risks on other banks than a private one does. To be specific, there is no systemic risk associated with the credit it extends. With a central bank present, therefore, the systemic risk becomes

$$
\frac{d}{2} \frac{n-2}{n-1} \sum_{i \in B} q_{i} \sum_{j \neq i} q_{j},
$$

where $B$ is the set of private banks. Thus, welfare is now:

$$
\begin{aligned}
W^{C}:= & a\left(\sum_{j \in N} q_{j}\right)-\frac{b}{2}\left(\sum_{j \in N} q_{j}\right)^{2}-\frac{c}{2}\left(\sum_{j \in N} q_{j}^{2}\right)-\frac{d}{2}\left(\sum_{j \in N} q_{j}^{2}\right) \\
& -d \frac{n-2}{n-1}\left(\sum_{i \in B} \sum_{\substack{j \in N \\
j \neq i}} q_{i} q_{j}\right)-\frac{d}{2} \frac{n-2}{n-1}\left(\sum_{j \in B} q_{C} q_{j}\right),
\end{aligned}
$$

where $q_{C}$ is the amount of credit extended by the central bank.

Similarly, the profit of each private bank $i \in B$ becomes:

$$
\pi_{i}^{C}=\left(a-b \sum_{j \in N} q_{j}\right) q_{i}-\frac{c}{2} q_{i}^{2}-\frac{d}{2} q_{i}^{2}-d \frac{n-2}{n-1}\left(\sum_{\substack{j \in B \\ j \neq i}} q_{j}\right) q_{i}-\frac{d}{2} \frac{n-2}{n-1} q_{C} q_{i} .
$$

Again, each private bank's profit is reduced by the externality imposed on it by other banks. However, this externality is lower from the lending activity of the central bank, which imposes external credit risk only.

I suggest that the homogeneous-good model of Section 3 is applicable also in this scenario, even though the banks involved now are heterogeneous. The banks differ only with respect to their systemic-risk properties. It is unlikely that consumers of payment services are concerned about the systemic risk associated with a particular bank's credit activity. Thus, from the viewpoint of the consumers, these banks provide homogeneous payment services.

\section{Social optimum}

In a discussion of the social optimum, there are only two different cases to consider. When it comes to efficiency, the banks' objectives are irrelevant. Thus, I need only distinguish between the case with ordinary banks only and the case with a central bank present. In the latter case, not surprisingly, the central bank with its more benign externality property performs the leading role: The effect of the central bank not causing any systemic risk is that this 
bank should provide a larger portion of total credit than any private bank. Recall that the $q$ s measure gross credit extended. Thus, it is not possible for any bank to supply a negative amount, i.e., to turn itself into a borrower in gross terms. When the risk externalities are sufficiently large relative to technological costs, the social optimum, therefore, calls for the central bank to be the only bank active in the payments system. Details of the social optimum are provided in Proposition A1 in the Appendix. We can, however, extract some essential properties of this optimum: ${ }^{11}$

\section{Proposition 1}

(i) If

$$
n \geq 4 \text {, and } \frac{d}{c} \leq 2,
$$

(ii) If

then private banks are present in social optimum.

$$
\frac{d}{c}>\frac{2}{3 n-8},
$$

then each of the $(n-1)$ private banks extends less credit in social optimum if the public bank is a central bank than if it is an ordinary bank.

Thus, unless externalities are very high, there is room for private banks in social optimum. But they will extend less credit when the central bank is present, particularly when $n$ is high. It is worth emphasizing that $\frac{d}{c} \leq 2$ is a sufficient condition, and by no means a necessary one, for private banks to be present in optimum.

\section{Equilibrium analysis}

In the analysis of equilibrium, both externality properties and objectives matter. Thus, I need to distinguish between all three of the scenarios outlined in Section 4.

Private banks only The case when all the banks operating in the interbank market are private highlights some essential features of an intra-day credit market. $^{12}$

\footnotetext{
${ }^{11}$ Part (i) of Proposition 1 follows directly from Proposition A1 in the Appendix, since $d_{1}$, which is used in that Proposition to delineate cases where private banks are inactive in social optimum, is shown always to be greater than $2 c$. Part (ii) follows from a comparison of the expressions in parts (i) and (ii) of Proposition A1.

${ }^{12}$ The equilibrium in the case of private banks only is described in detail in Proposition A2 in the Appendix. The present result follows from a comparison of Propositions A1 and A2.
} 
Proposition 2 When $n \geq 4$ identical private banks extend credit on the intraday credit market, credit is oversupplied in equilibrium, relative to the social optimum, if and only if

$$
\frac{d}{b}>\frac{1}{n-2}
$$

There are two contrasting forces at play producing this result. First, there is the effect of imperfect competition, leading in isolation to an undersupply of credit. Second, there is the effect of risk externalities (external direct risk and systemic risk, combined), leading in isolation to an oversupply of credit: Although each bank does take into account how it can reduce the effect of other banks' externalities on its own profit, it does not account for the externalities it itself imposes on the other banks. An increase in $n$, the number of banks, decreases the downward distortion caused by imperfect competition and increases the upward one caused by the risk externalities. An increase in $d$ increases the distortion due to risk externalities. ${ }^{13}$ Thus, even if there is imperfect competition in the payments market, there is not necessarily an undersupply of credit in this market, due to the risk externalities involved.

The demand for payment services is viewed by many as being rather inelastic, implying in our model that $b$ is large. We see from Proposition 2 that, the higher is $b$, the less is the scope for oversupply of credit in equilibrium when all banks are private.

Introducing a public bank The next scenario has a publicly owned, welfaremaximizing bank pitted against $(n-1)$ private ones; thus, the number of banks is kept unaltered relative to the previous analysis. Apart from the ownership status and the difference in the banks' objectives that this entails, the banks are (still) identical.

In cases where private banks, if left alone, would oversupply credit, it becomes relevant for the public firm to reduce total credit supply by supplying less credit than a private bank would. This happens, as we see in Proposition 3 below, when the risk externalities are sufficiently severe. The restriction $d<c$ is imposed here to ensure equilibrium stability in the sense of Dixit (1986); see the discussion after Proposition 4 below. ${ }^{14}$

\footnotetext{
${ }^{13}$ As indicated in the Introduction, the observation that a monopoly or an oligopoly with negative externalities may overproduce relative to the social optimum is well known from other contexts, such as pollution. Häckner and Nyberg (1996), like I do, discuss an oligopoly with negative externalities between firms. In their model, however, the negative externality works through the demand side, while here, it works through costs.

${ }^{14}$ Parts (i) and (iii) of Proposition 3 follow straightforwardly from Proposition A3 in the Appendix. A proof of part (ii), as well as an exact delineation of cases of oversupply of credit, are found in the Appendix.
} 
Proposition 3 Assume $d<c$.

(i) The public bank is active in equilibrium if and only if, in addition,

$$
\frac{d}{b+c}<\frac{n-1}{n(n-2)} \text {. }
$$

(ii) There is oversupply of credit in equilibrium if the public bank is inactive and also in some cases where it is active.

(iii) The public bank extends a larger amount of credit in equilibrium than a private bank if and only if

$$
\frac{d}{b}<\frac{1}{n-1}
$$

When the public bank is also the central bank I turn, finally, to the case where the public bank not only is a welfare-maximizer but also is the central bank and as such is not able to become illiquid. ${ }^{15}$ While this creates an asymmetry among the banks, with the central bank exerting less externalities on other banks than any of the private banks does, the central bank may still suffer from a lack of instruments in this case: If risk externalities are high and a reduction in credit is called for, the central bank may end up with a lower activity level than its private counterpart, despite its superior externality properties. In particular, I have:

\section{Proposition 4}

(i) The central bank is active in equilibrium if and only if

$$
\frac{d}{b+c}<\frac{2(n-1)}{n(n-3)}
$$

(ii) There may be oversupply of credit in equilibrium even when the central bank is active, and there may undersupply of credit even when the central bank is inactive.

(iii) In equilibrium, the central bank extends a smaller amount of credit than a private bank if and only if:

$$
\frac{d}{b}>\frac{2(n-1)}{n(n-2)}
$$

Note in Proposition 4 that, contrary to the previous case, when the public bank is a central bank, the equilibrium is always stable. The reason is that equilibrium non-stability is related to conflicts of interests among the firms in the market. This conflict is most striking in the previous case of one bank

\footnotetext{
${ }^{15}$ Accounts from history indicate that central banking may be profitable in some circumstances; see, e.g., the discussion in Rolnick et al. (1998, 2000). Thus, a discussion of a profit-maximizing, rather than welfare-maximizing central bank, with all of such a bank's benign risk externalities, may be of interest, even though it is skipped in the present exposition.
} 
being welfare-maximizing but otherwise identical to the other banks. In the present case of the welfare-maximizing bank, in addition, exerting less risk externalities from its lending activities than the other banks do, the conflict is reduced, since also the private banks benefit in part from the central bank having a large share of the market.

Comparing Proposition 4 with Proposition 1(ii), we see how differently an increase in the risk-externality parameter $d$ affects the first-best optimum and the mixed-oligopoly equilibrium. In optimum, an increase in the systemic risk implies the central bank taking on a larger share of the market. In equilibrium, instead, the central bank has to reduce its activities in order to correct for the oversupply from the private banks. In fact, in the extreme case, the first best calls for the central bank to be the only bank in the market, while in equilibrium, the central bank is, quite to the contrary, the only bank that is inactive. ${ }^{16}$ As part (ii) of the Proposition witnesses, the central bank chooses to be inactive even in some cases when the resulting equilibrium outcome features an undersupply of credit relative to the social optimum.

Part (iii) of Proposition 4 addresses the question asked earlier, in the presentation of the risk externalities in Section 2: Will the central bank extend more or less credit than the private banks? It has incentives to extend more credit because its credit activities constitute less social risk than that of the others, and because of the traditional oligopoly undersupply effect. The former of these is strong when there are many private banks, while the latter is strong when there are few of them. But it also has incentives to extend less credit in order to correct for the risk externalities emanating from the private banks' credit activities. When the risk is large enough, this latter effect will surely dominate and the central bank, despite its lower externalities, ends up with a lower activity level than the others. An ordinary public bank, on the other hand, is less likely to end up with a higher quantity than the private banks, since it does not have an externality advantage over them as the central bank does. By comparing expressions in Propositions 3 and 4, I find: ${ }^{17}$

\section{Proposition 5 Suppose $d<c$.}

(i) If, in addition,

$$
\frac{1}{n-1}<\frac{d}{b}<\frac{2(n-1)}{n(n-2)},
$$

then, in equilibrium, the public bank is larger than the private banks when it is also the central bank, but smaller than them when it is an ordinary bank.

\footnotetext{
${ }^{16}$ The exact condition for this extreme case to occur is given in Eq. 3 in the Appendix.

${ }^{17}$ The restriction $d<c$, although not applied in Proposition 4, is made here in order to compare the results there with those of Proposition 3, where this restriction is imposed to ensure equilibrium stability.
} 
(ii) If, in addition,

$$
\frac{n-1}{n(n-2)}<\frac{d}{b+c}<\frac{2(n-1)}{n(n-3)},
$$

then the publicly owned bank is active in equilibrium if it is also a central bank but not if it is an ordinary bank.

Proposition 5 indicates that a central bank has a larger role to play than an ordinary, publicly owned bank has, not only in the first-best optimum, but also in the second-best equilibrium: In general, a central bank extends more credit than an ordinary public bank. And more particularly, there are cases where an ordinary public bank would choose not to operate in order to counteract an oversupply by the private banks, but where the beneficial externality properties of a central bank would make room for its active participation. This difference comes about partly because there are less overall externalities when one of the banks is a central bank, which calls for increased total credit, and partly because the central bank's credit is particularly beneficial for welfare. The change in private banks' behavior as we move from a regime with an ordinary public bank to one with a central bank is caused by the banks' quantities being strategic substitutes, in the sense of Bulow et al. (1985): If the public bank expands its output, then the private banks contract theirs, and vice versa.

However, the way the private banks and the public bank react to an increase differs between the two cases of an ordinary public bank and a central bank. Because the introduction of the central bank into the market reduces the systemic risk, the private banks react to an increase in risk in a much more aggressive way than in the case when the public bank share their risk properties. Actually, this amounts to an overreaction on the part of the private banks. Alternatively, compared to its private counterparts, the central bank, with its benign risk externalities, chooses to hold on to its extension of credit, as the risk increases, to a much larger extent than if it were an ordinary bank. The decrease in externalities caused by the introduction of the central bank is asymmetric, which calls for a decrease in private banks' credit in social optimum, a decrease which is too hard to implement for a central bank with only one instrument, as in my model, viz. its own credit activity. The outcome is that, even though the case of a central bank has less risk externalities overall and therefore the social optimum calls for a higher level of total credit than in the case of an ordinary public bank, an oversupply of equilibrium credit may occur with the central bank, even in cases where, with an ordinary public bank, there would be an undersupply of credit in equilibrium.

\section{Concluding remarks}

This paper, contrary to most of the existing literature on the payments system, suggests that considering a large-value payment system as an interbank credit 
oligopoly is a worthwhile exercise and presents an analysis of strategic interaction in such a market. Particular emphasis is put on how a central bank, with more benign objectives and externalities than other banks, performs in the equilibrium of such an oligopoly. Thus, the analysis may also, more generally, have a bearing on the understanding of the performance of publicly owned firms in this kind of mixed oligopolies: The present analysis shows how the market equilibrium is affected by introducing a public firm that is not only a welfare maximizer but whose production carries a lower social cost than that of the private firms in the market.

An analysis of the payments system limited in scope to the social optimum would conclude that the central bank ought to engage heavily as a regular participant in the interbank credit market. The present analysis shows the importance of performing an equilibrium analysis as well: For sufficiently high risk externalities and an inability, on the part of the central bank, to instruct each private bank its extension of credit, the correct thing for the central bank to do is to stay out and stick to the role as supervisor and coordinator.

Acknowledgements Thanks to an anonymous referee for insightful comments. Thanks also to Steinar Holden, Eivind Kloster-Jensen, Eirik Kristiansen, Diderik Lund, Kalle Moene, Tone Ognedal, Bent Vale, and seminar participants at the Norwegian School of Economics and Business Administration and the University of Oslo for comments and discussions, and to Nina Skrove Falch for research assistance. Parts of the research have been done during visits at Norges Bank, Tilburg University, and the University of California, Berkeley. Travel grants from the Research Council of Norway, the US-Norway Fulbright Foundation, and Professor Keilhau's Memorial Fund are greatly appreciated. The author is an associate of the ESOP centre at the University of Oslo. The ESOP centre receives funding from the Research Council of Norway.

Open Access This article is distributed under the terms of the Creative Commons Attribution Noncommercial License which permits any noncommercial use, distribution, and reproduction in any medium, provided the original author(s) and source are credited.

\section{Appendix}

This Appendix contains detailed results, and their proofs, of the analysis of this model.

\section{Proposition A1 Social optimum}

(i) With identical banks in the intra-day market, the social optimum is that each of the n banks supplies:

$$
q_{P}^{*}=\frac{a}{b n+c+d(2 n-3)} .
$$

(ii) Let $q_{C c}^{*}, q_{C p}^{*}$ and $Q_{C}^{*}$ denote the socially optimum amount of credit offered by the central bank, a private bank, and in total, respectively, in the case with $(n-1)$ private banks and one central bank. Define:

$$
D_{C}^{*}:=d\left[8 b+n^{2}(8 c-d)\right]+4(n-1)[c(b n+c)-2 d(3 c-d)] .
$$


Let $d_{1}>2 c$ be defined for $n \geq 5$ by:

$$
d_{1}= \begin{cases}\frac{2\left[\tau+\sqrt{\tau^{2}+c(b n+c)(n-1)\left(n^{2}-8 n+8\right)}\right]}{\frac{2 c(n-1)}{n-4},}, & \text { if } n \geq 7, \\ n^{2}-8 n+8 & \text { if } 5 \leq n \leq 6 .\end{cases}
$$

where $\tau:=2\left[b+c\left(n^{2}-3 n+3\right)\right]$.

(a) if $n=4$, or if $n \geq 5$ and $d<d_{1}$, then the social optimum is given by:

$$
\begin{aligned}
q_{C c}^{*} & =\frac{2 a}{D_{C}^{*}}\left[2 c(n-1)+d\left(n^{2}-5 n+8\right)\right], \\
q_{C p}^{*} & =\frac{2 a}{D_{C}^{*}}[2 c(n-1)-d(n-4)], \text { and } \\
Q_{C}^{*} & =\frac{4 a}{D_{C}^{*}}[c n(n-1)+2 d] ;
\end{aligned}
$$

(b) if $n=3$, or if $n \geq 5$ and $d \geq d_{1}$, then private banks do not extend credit in social optimum, i.e.,

$$
\begin{aligned}
& q_{C p}^{*}=0, \text { and } \\
& q_{C c}^{*}=Q_{C}^{*}=\frac{a}{b+c+d} .
\end{aligned}
$$

Proof

(i) From the welfare expression in Section 3, I get the first-order condition for bank $i$ 's optimum amount of credit:

$$
\frac{d W}{d q_{i}}=a-b\left(\sum_{j \in N} q_{j}\right)-c q_{i}-d q_{i}-2 d \frac{n-2}{n-1}\left(\sum_{\substack{j \in N \\ j \neq i}} q_{j}\right)=0 .
$$

By symmetry, $q_{i}=q=\frac{Q}{n}$, for each $i$. Thus, the above equation reduces to:

$$
a-b n q-c q-d(2 n-3)=0,
$$

from which I obtain the expression for $q_{P}^{*}$.

(ii) The relevant welfare expression in this case is $W^{C}$ in Section 4. Because of the symmetry of the private banks, the first-order condition for a social optimum with respect to the central bank's credit quantity is:

$$
a-b\left[q_{c}+(n-1) q_{p}\right]-c q_{c}-d q_{c}-d(n-2) q_{p}-\frac{d}{2}(n-2) q_{p},
$$


while the first-order condition with respect to each private bank's quantity is:

$$
\begin{aligned}
& a-b\left[q_{c}+(n-1) q_{p}\right]-c q_{p}-d q_{p}-d \frac{n-2}{n-1}\left[q_{c}+2(n-2) q_{p}\right] \\
& \quad-\frac{d}{2} \frac{n-2}{n-1} q_{c} .
\end{aligned}
$$

Supposing an interior solution, I can now solve the following system of first-order conditions to find welfare maximum:

$$
\left(\begin{array}{c}
(b+c+d) \quad\left[b(n-1)+\frac{3(n-2)}{2} d\right] \\
\left(b+\frac{3(n-2)}{2(n-1)} d\right)\left[b(n-1)+c+\frac{2 n^{2}-7 n+7}{n-1} d\right]
\end{array}\right)\left(\begin{array}{l}
q_{C c} \\
q_{C p}
\end{array}\right)=\left(\begin{array}{l}
a \\
a
\end{array}\right),
$$

where the first (second) equation is the first-order condition with respect to the quantity of the central bank, $q_{C c}$ (the quantity of a private bank, $\left.q_{C p}\right)$. The solution is the one outlined in part (ii)(a) of the Proposition. The determinant of the coefficient matrix is $D_{C}^{*}$, given in the Proposition. Second-order conditions for an optimum require that $D_{C}^{*}>0$, which holds if $3 \leq n \leq 6$ or, for $n \geq 7$, if

$$
d \leq \frac{2\left[\tau+\sqrt{\tau^{2}+c(b n+c)(n-1)\left(n^{2}-8 n+8\right)}\right]}{n^{2}-8 n+8},
$$

where $\tau$ is defined in Proposition A1. In addition, an interior solution requires that quantities be non-negative, in particular that

$$
2 c(n-1)-d(n-4) \geq 0 .
$$

This is never satisfied for $n=3$ and always satisfied for $n=4$. For $n \geq 7$, this condition is weaker than Eq. 2. Thus, we get the condition stated in the Proposition.

When $D_{C}^{*} \leq 0$, which can only occur if $n \geq 7$, optimum is one of two possible corner solutions: either the central bank alone and $q_{C p}=0$; or $(n-1)$ private banks and $q_{C c}=0$. Comparing the welfare levels obtainable in each of these two cases, the former case is found to be preferred to the latter if $d \geq c(n-2) /(n-4)$, a condition which is implied by $D_{C}^{*} \leq 0$. Thus, when the solution is not interior, social optimum is the central bank alone.

Finally, note that, clearly, $d_{1}>2 c$ if the right-hand side of Eq. 2 is. This expression is decreasing in $n$, and as $n$ goes to infinity, it goes to

$$
2\left[2 c+\sqrt{4 c^{2}+b c}\right]>8 c
$$

Thus, $d_{1}>2 c$. 
Proposition A2 (Equilibrium with private banks only) If $n$ identical private banks extend credit on the intra-day credit market, then, in equilibrium, each bank supplies

$$
q_{P}^{e}=\frac{a}{b(n+1)+c+d(n-1)} .
$$

Proof From the profit expression in Section 3, I get each bank's first-order condition:

$$
\frac{d \pi_{i}}{d q_{i}}=a-b\left(\sum_{j \in N} q_{j}\right)-b q_{i}-c q_{i}-d q_{i}-d \frac{n-2}{n-1}\left(\sum_{\substack{j \in N \\ j \neq i}} q_{j}\right)=0 .
$$

Again, by symmetry, all $q$ s are the same and equal to $\frac{Q}{n}$. Thus, I write the first-order condition as:

$$
a-b(n+1) q-c q-d(n-1)=0,
$$

and I obtain the expression for $q_{P}^{e}$ in the Proposition.

Proposition A3 (Introducing a public bank) Assume $d<c$. Let $q_{O o}^{e}, q_{O p}^{e}$, and $Q_{O}^{e}$ denote the equilibrium amount of credit offered by the public bank, a private bank, and in total, respectively, in the case of $(n-1)$ identical private banks and one publicly owned, welfare-maximizing bank. Define:

$$
D_{O}:=n^{2}(b+d)(c-d)+(n-1)\left[(b-c+2 d)^{2}+c(2 b+d)\right]+b(5 c+2 d) .
$$

(a) If

$$
d<\min \left[c, \frac{(b+c)(n-1)}{n(n-2)}\right],
$$

then, in equilibrium, each private bank lends

$$
q_{O p}^{e}=\frac{a}{D_{0}}[c(n-1)+d],
$$

the public bank lends

$$
q_{O o}^{e}=\frac{a}{D_{0}}[(b+c)(n-1)-d n(n-2)],
$$

and total credit supply equals

$$
Q_{O}^{e}=\frac{a}{D_{0}}\left[(b+c)(n-1)+(c-d)(n-1)^{2}+d n\right] .
$$

(b) If

$$
\frac{(b+c)(n-1)}{n(n-2)} \leq d \leq c,
$$


then, in equilibrium, each private bank lends

$$
q_{O p}^{e}=\frac{a}{b n+c+d(n-2)},
$$

the public bank is inactive,

$$
q_{O o}^{e}=0
$$

and total credit supply equals

$$
Q_{O}^{e}=\frac{a(n-1)}{b n+c+d(n-2)} .
$$

\section{Proof}

(a) Each private bank maximizes its payoff with respect to own credit, while the public bank maximizes welfare with respect to its credit. Thus, following the proof of Proposition A1(i), and since the $(n-1)$ private banks are symmetric, I can write the welfare-maximizing public bank's first-order condition as:

$$
a-b\left[(n-1) q_{p}+q_{o}\right]-c q_{o}-d q_{o}-2 d(n-2) q_{p}=0
$$

Similarly, I can write each private bank's first-order condition as:

$a-b\left[(n-1) q_{p}+q_{o}\right]-b q_{p}-c q_{p}-d q_{p}-d \frac{n-2}{n-1}\left[(n-2) q_{p}+q_{o}\right]=0$

The two equations can be combined into the following system:

$$
\left(\begin{array}{cc}
\left(b+\frac{d(n-2)}{n-1}\right) & \left(b n+c+\frac{d(n-2)^{2}}{n-1}\right) \\
(b+c+d) & {\left[\begin{array}{ll}
b(n-1)+2 d(n-2)
\end{array}\right]}
\end{array}\right)\left(\begin{array}{l}
q_{O o} \\
q_{O p}
\end{array}\right)=\left(\begin{array}{l}
a \\
a
\end{array}\right),
$$

where the first (second) equation is the first-order condition of a private (the public) bank. Equilibrium stability requires $D_{O}>0$ (see Dixit 1986), which is met here under the maintained assumption $d<c$. The solution to the equation system is given in the Proposition, and it holds if all the $q \mathrm{~s}$ are non-negative; the condition for this is the one given. The quantity of total credit equals $q_{O o}^{e}+(n-1) q_{O p}^{e}$.

(b) The optimum amount of credit for the public bank is now zero. Taking this into account in the first-order condition of a private bank, the expression in the Proposition is obtained. The quantity of total credit equals $(n-1) q_{O p}^{e}$.

Proof of part (ii) of Proposition 3 First, I check the case of part (b) of Proposition A3, supposing

$$
\frac{d}{b+c} \geq \frac{n-1}{n(n-2)}
$$


Comparing $(n-1) q_{O p}^{e}$ from Proposition A3 with $n q_{P}^{*}$ from Proposition A1, I find that there is oversupply if the weaker condition

$$
d \geq \frac{b n+c}{n^{2}-3 n+3}
$$

holds; the latter condition is weaker because, in the two righthand-side expressions, the denominator of the latter is less than or equal to that of the former and its numerator is greater. Thus, there is always oversupply when the public bank is inactive.

In the case of part (a) of Proposition A3, where

$$
d<\min \left[c, \frac{(b+c)(n-1)}{n(n-2)}\right],
$$

I compare $Q_{O o}^{e}$ from Proposition A3 with $n q_{P}^{*}$ from Proposition A1 and find that there is oversupply for $n \geq 4$ if and only if $d>d_{2}$, where

$$
d_{2}:=\frac{1}{2}\left(\frac{c(n-1)}{n-3}+\frac{b}{n-1}\right)-\sqrt{\frac{1}{4}\left(\frac{c(n-1)}{n-3}+\frac{b}{n-1}\right)^{2}-\frac{b c\left(n^{2}+4 n+1\right)}{(n-1)^{2}(n-3)}},
$$

is the lower root solving the equation $Q_{O o}^{e}=n q_{P}^{*}$ with respect to $d$, provided the equation has real roots; the higher root does not satisfy the above restriction. When $n=3$, there is always oversupply in equilibrium.

Proposition A4 (When the public bank is a central bank) Let $q_{C c}^{e}, q_{C p}^{e}$, and $Q_{C}^{e}$ denote the equilibrium amount of credit offered by the central bank, a private bank, and in total, respectively, in the case with $(n-1)$ private banks and one central bank. Define:

$$
D_{C}^{e}:=4(n-1)\left[b^{2}+c^{2}+b c(n+1)+c d(n-1)\right]+d\left[4 b(2 n-1)+4 c+d n^{2}\right] .
$$

(a) If

$$
\frac{d}{b+c}<\frac{2(n-1)}{n(n-3)},
$$

then, in equilibrium, each private bank lends

$$
q_{C p}^{e}=\frac{2 a}{D_{C}^{e}}[2 c(n-1)+d n]
$$

the central bank lends

$$
q_{C c}^{e}=\frac{2 a}{D_{C}^{e}}[2(b+c)(n-1)-d n(n-3)],
$$

and total credit supply equals

$$
Q_{C}^{e}=\frac{4 a}{D_{C}^{e}}[(b+c n)(n-1)+d n] .
$$


(b) If

$$
\frac{d}{b+c} \geq \frac{2(n-1)}{n(n-3)}
$$

then, in equilibrium, the central bank is inactive and the outcome is the same as the one reported in Proposition A3(b).

Proof The central bank's first-order condition in part (a) is identical to Eq. 1 above. From a private bank's profit in the case of a central bank, $\pi_{i}^{C}$ in Section 4, each private bank's first-order condition is, by symmetry among the private banks, given by:

$$
a-b\left[(n-1) q_{p}+q_{c}\right]-b q_{p}-c q_{p}-d q_{p}-d \frac{(n-2)^{2}}{n-1} q_{p}-\frac{d n-2}{2} \frac{n}{n-1} q_{c}=0 .
$$

Supposing non-negative quantities in equilibrium, the equilibrium is thus found by solving the following system:

$$
\left(\begin{array}{cc}
(b+c+d) & {\left[b(n-1)+\frac{3}{2}(n-2) d\right]} \\
\left(b+\frac{n-2}{2(n-1)} d\right)\left(b n+c+\frac{n^{2}-3 n+3}{n-1} d\right)
\end{array}\right)\left(\begin{array}{l}
q_{C c} \\
q_{C p}
\end{array}\right)=\left(\begin{array}{l}
a \\
a
\end{array}\right),
$$

where the first (second) equation is the first-order condition of the central bank, $q_{C c}$ (a private bank, $q_{C p}$ ). The resulting outcome is the one outlined. Quantities are non-negative if the numerator of $q_{C c}^{e}$ is, which gives rise to the condition distinguishing parts (a) and (b).

Proof of part (ii) of Proposition 4 Consider first the case where the central bank is active in equilibrium. Given the supposition that the equilibrium outcome is interior, I first compare the total equilibrium supply of part (a) of Proposition A4 with the optimum total supply in Proposition A1(ii)(a), which covers the subcase where the social optimum is interior, too. This comparison shows that there is oversupply in this subcase if and only if

$$
\left[\sqrt{\alpha^{2}+8 b c n(n-2)}-\alpha\right] \frac{n-1}{2 n(n-2)}<d<\frac{2 c(n-1)}{n-4},
$$

where $\alpha:=b(n-4)+2 c(n-1)(n-2)$. The second inequality is always satisfied when the social optimum is interior, by Proposition A1(ii). Secondly, I compare the total equilibrium supply of part (a) of Proposition A4 with the optimum supply in Proposition A1(ii)(b), for the subcase when the optimum is for the central bank to be alone. This comparison shows that there is oversupply in this subcase if and only if

$$
\frac{d}{c}<\frac{2(n-1)}{n-4} .
$$

Combining the two subcases, we find that the former condition holds in both. 
Consider next the case where the central bank is inactive in equilibrium. In order to show that there may be undersupply in equilibrium it suffices to compare the equilibrium outcome with the social optimum in the extreme case of

$$
d>\max \left[d_{1}, \frac{2(b+c)(n-1)}{n(n-3)}\right],
$$

when optimum calls for the central bank to be the only bank in the market, while in equilibrium the central bank is, quite to the contrary, the only bank that is inactive. The comparison between equilibrium supply and optimum reveals that there is undersupply if, in addition to Eq. 3, also the following holds:

$$
d>b-c(n-2) .
$$

Comparing this condition with Eq. 3 reveals that it is not vacuous and that indeed cases exist where the central bank is inactive in equilibrium and still there is undersupply of credit.

\section{References}

Angelini P (1998) An analysis of competitive externalities in gross settlement systems. J Bank Finance 22:1-18

Angelini P, Maresca G, Russo D (1996) Systemic risk in the netting system. J Bank Finance 20:853868

Bech ML, Garratt R (2003) The intraday liquidity management game. J Econ Theory 109:198-219

Berger AN, Hancock D, Marquardt JC (1996) A framework for analyzing efficiency, risks, costs, and innovations in the payments system. J Money Credit Bank 28:696-732

Board of Governors of the Federal Reserve System (2008) Policy on payment system risk. Fed Regist 73:79109-79127

Buchanan JM (1969) External diseconomies, corrective taxes, and market structure. Am Econ Rev 59:174-177

Bulow JI, Geanakoplos JD, Klemperer PD (1985) Multimarket oligopoly: strategic substitutes and complements. J Polit Econ 93:488-511

Calomiris CW, Kahn CM (1996) The efficiency of self-regulated payments systems: learning from the Suffolk System. J Money Credit Bank 28:766-797

Committee on Payment and Settlement Systems (2009) Statistics on payment and settlement systems in selected countries-figures for 2008. CPSS Publications no 88. Bank for International Settlements, Basel

Crane DA (2005) Harmful output in the antitrust domain: lessons from the tobacco industry. Georgia Law Rev 39:321-410

De Fraja G, Delbono F (1990) Game theoretic models of mixed oligopoly. J Econ Surv 4:1-17

Dixit A (1986) Comparative statics for oligopoly. Int Econ Rev 27:107-122

Freixas X, Parigi B (1998) Contagion and efficiency in gross and net interbank payment systems. J Financ Intermed 7:3-31

Freixas X, Parigi B, Rochet J-C (2000) Systemic risk, interbank relations, and liquidity provision by the Central Bank. J Money Credit Bank 20:611-638

Fujiki H, Green EJ, Yamazaki A (2008) Incentive efficient risk sharing in a settlement mechanism. J Econ Theory 142:178-195

Gelfand MD, Lindsey DE (1989) The simple microanalytics of payments system risk. Finance and economics discussion paper 61, Federal Reserve Board, Washington, DC

Green EJ, Todd RM (2001) Thoughts on the Fed's role in the payments system. Federal Reserve Bank of Minneapolis Q Rev 25(1):12-27 
Häckner J, Nyberg S (1996) Vanity and congestion: a study of reciprocal externalities. Economica 63:97-111

Hammer PJ (2000) Antitrust beyond competition: market failures, total welfare, and the challenge of of intramarket second-best tradeoffs. Mich Law Rev 98:849-925

Hancock D, Wilcox JA (1996) Intraday management of bank reserves: the effects of caps and fees on daylight overdrafts. J Money Credit Bank 28:870-908

Holthausen C, Rochet J-C (2006) Efficient pricing of large value interbank payment systems. J Money Credit Bank 38:1797-1818

Humphrey D, Pulley LB, Vesala JM (1996) Cash, paper, and electronic payments: a cross-country analysis. J Money Credit Bank 28:914-939

Humphrey D, Kim M, Vale B (2001) Realizing the gains from electronic payments: costs, pricing, and payment choice. J Money Credit Bank 33:216-234

Kahn CM, Roberds W (1998) Payment system settlement and bank incentives. Rev Financ Stud 11:845-870

Kahn CM, McAndrews J, Roberds W (2003) Settlement risk under gross and net settlement. J Money Credit Bank 35:591-608

Kaufman GG (1994) Bank contagion: a review of the theory and evidence. J Financ Serv Res $8: 123-150$

Kauko K (2009) The mixed duopoly of large-value payment systems. IRJFE 24:153-166

Lacker J (2008) Payment economics and the role of central banks. In: Haldane AG, et al (eds) The future of payment systems. Routledge, London, pp 68-72

Leslie CR (1993) Achieving efficiency through collusion: a market failure defence to horizontal price-fixing. Calif Law Rev 81:243-292

Rochet J-C, Tirole J (1996a) Controlling risk in payment systems. J Money Credit Bank 28:832862

Rochet J-C, Tirole J (1996b) Interbank lending and systemic risk. J Money Credit Bank 28:733-762

Rolnick AJ, Smith BD, Weber WE (1998) Lessons from a laissez-faire payments system: the Suffolk Banking System (1825-58). Federal Reserve Bank of St. Louis Rev 80(3):105-116

Rolnick AJ, Smith BD, Weber WE (2000) The Suffolk Bank and the panic of 1837. Federal Reserve Bank of Minneapolis Q Rev 24(2):3-13

Shen P (1997) Settlement risk in large-value payments systems. Federal Reserve Bank of Kansas City Econ Rev 82(2):45-62 